\section{Correspondence on 'Safety and tolerability of nintedanib in patients with systemic sclerosis- associated interstitial lung disease: data from the SENSCIS trial'}

The Safety and Efficacy of Nintedanib in Systemic Sclerosis (SENSCIS) trial, ${ }^{1}$ published in May 2019 in New England Journal of Medicine, analysed the efficacy and safety of nintedanib in the treatment of systemic sclerosis-related interstitial lung disease (SSc-ILD) over 52 weeks. A reanalysis of the safety and tolerability data was recently published in Annals of the Rheumatic Diseases. $^{2}$ In both articles, we could not find information on the incidence of serious infections and serious respiratory tract infections.

Further safety results of the SENSCIS trial, using a wider time frame than the original publications (i.e., up to 100 weeks of follow-up), are accessible at ClinicalTrials.gov website since December 2019. ${ }^{3}$ In a closer look at the table reporting serious adverse events (you must do the math), there were 34 infections in nintedanib versus 14 in placebo group (each group had 288 patients). ${ }^{1}$ Notwithstanding the fact that this is not the primary outcome of the study (what may affect the interpretation of the $\mathrm{p}$ values), the risk of serious infections is significantly higher in nintedanib group (risk ratio, $2.43,95 \%$ confidence interval [CI], 1.33 to $4.43, \mathrm{p}=0.003$; risk difference, $6.9 \%, 95 \% \mathrm{CI}, 2.1$ to $11.8 \%)$. Bacterial or viral respiratory tract infections represented apparently $18 / 34(53 \%)$ and $7 / 14(50 \%)$ of serious infections in nintedanib and placebo groups, respectively. Eleven cases of serious infectious pneumonia were reported with nintedanib comparing with two in placebo arm, ${ }^{3}$ representing a risk ratio of 5.50 (95\% CI, 1.23 to $24.59, \mathrm{p}=0.012$; risk difference, $3.1 \%$, $95 \%$ CI, 0.4 to $5.9 \%$ ). Two fatalities in nintedanib arm were attributed to pneumonia after adjudication of the causes of deaths. ${ }^{1}$

It is possible that the net clinical beneficial effects of nintedanib are restricted to patients with the usual interstitial pneumonia (UIP)-like pattern on high-resolution CT (HRCT). In systemic sclerosis, the overwhelming majority of patients presents the non-specific interstitial pneumonia pattern on HRCT. In the INBUILD trial, ${ }^{4}$ which included patients with progressive ILD of different aetiologies, randomisation of patients was stratified by the pattern on HRCT, and mortality and serious adverse events (SAEs) seem to have behaved differently in the subgroups. In non-UIP-like pattern subgroup, the incidence of fatality was 4/126 (3.2\%) with nintedanib and 1/125 (0.8\%) with placebo, while in UIP subgroup it was 7/206 (3.4\%) with nintedanib and $16 / 206(7.8 \%)$ with placebo (at 52 weeks; test of heterogeneity of odds ratios (ORs), $\mathrm{p}=0.036)$. SAEs occurred in 44/126 $(34.9 \%)$ patients with nintedanib versus $33 / 125$ (26.4\%) with placebo in the non-UIP subgroup; in UIP subgroup, SAEs occurred in $63 / 206$ (30.6\%) patients with nintedanib versus 77/206 (37.4\%) with placebo (heterogeneity of ORs, $p=0.041$ ). Therefore, there may be a shift in the safety pattern, with nintedanib causing a higher incidence of complications in non-UIP-like ILD and reducing clinically serious events in UIP-like ILD.

Despite the observed effect of nintedanib in reducing the loss of forced vital capacity in SSc-ILD, changes in pulmonary function tests are still surrogate endpoints. Further studies are necessary to prove the safety and the capacity of nintedanib in improving clinical outcomes that represent the burden of disease to patients with SSc-ILD.

\section{Markus Bredemeier $\odot$}

Rheumatology Service, Hospital Nossa Senhora da Conceição, Grupo Hospitalar Conceição, Porto Alegre, Rio Grande do Sul, Brazil

Correspondence to Dr Markus Bredemeier, Rheumatology Service, Hospital Nossa Senhora da Conceição, Grupo Hospitalar Conceição, Porto Alegre, Rio Grande do Sul 91350-200, Brazil; markbred@terra.com.br

Contributors MB is the sole contributor to this letter and takes full responsibility for its content.

Funding The authors have not declared a specific grant for this research from any funding agency in the public, commercial or not-for-profit sectors.

Competing interests None declared.

Patient and public involvement Patients and/or the public were not involved in the design, or conduct, or reporting, or dissemination plans of this research.

Patient consent for publication Not required.

Provenance and peer review Not commissioned; internally peer reviewed.

(c) Author(s) (or their employer(s)) 2020. No commercial re-use. See rights and permissions. Published by BMJ.

\section{Check for updates}

To cite Bredemeier M. Ann Rheum Dis Epub ahead of print: [please include Day Month Year]. doi:10.1136/annrheumdis-2020-218911

Received 18 August 2020

Accepted 22 August 2020

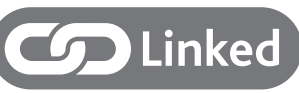

- http://dx.doi.org/10.1136/annrheumdis-2020-218960

Ann Rheum Dis 2020;0:1. doi:10.1136/annrheumdis-2020-218911

ORCID iD

Markus Bredemeier http://orcid.org/0000-0002-7911-593X

\section{REFERENCES}

1 Distler O, Highland KB, Gahlemann M, et al. Nintedanib for systemic sclerosisassociated interstitial lung disease. N Engl J Med 2019;380:2518-28.

2 Seibold JR, Maher TM, Highland KB, et al. Safety and tolerability of nintedanib in patients with systemic sclerosis-associated interstitial lung disease: data from the SENSCIS trial. Ann Rheum Dis 2020. doi:10.1136/annrheumdis-2020-217331. [Epub ahead of print: 05 Aug 2020].

3 ClinicalTrials.gov. A trial to compare nintedanib with placebo for patients with scleroderma related lung fibrosis. Available: https://clinicaltrials.gov/ct2/show/results/ NCT02597933 [Accessed 10 Aug 2020].

4 Flaherty KR, Wells $A U$, Cottin V, et al. Nintedanib in progressive fibrosing interstitial lung diseases. N Engl J Med 2019;381:1718-27. 